\title{
Article \\ Metabolomic Profiles of Essential Oils from Selected Rosa Varieties and Their Antimicrobial Activities
}

\author{
Esraa A. Elhawary ${ }^{\dagger}\left(\mathbb{D}\right.$, Nada M. Mostafa ${ }^{*}+{ }^{\mathbb{C}}$, Rola M. Labib and Abdel Nasser Singab * \\ Department of Pharmacognosy, Faculty of Pharmacy, Ain-Shams University, Cairo 11566, Egypt; \\ esraa.elhawary@pharma.asu.edu.eg (E.A.E.); rolamilad@pharma.asu.edu.eg (R.M.L.) \\ * Correspondence: nadamostafa@pharma.asu.edu.eg (N.M.M.); dean@pharma.asu.edu.eg (A.N.S.); \\ Tel.: +20-102-566-6872 (N.M.M.); +20-100-503-6231 (A.N.S.) \\ + These authors contributed equally to this work.
}

check for updates

Citation: Elhawary, E.A.; Mostafa, N.M.; Labib, R.M.; Singab, A.N. Metabolomic Profiles of Essential Oils from Selected Rosa Varieties and Their Antimicrobial Activities. Plants 2021, 10, 1721. https://doi.org/ $10.3390 /$ plants10081721

Academic Editor: Stefania Garzoli

Received: 24 July 2021

Accepted: 18 August 2021

Published: 20 August 2021

Publisher's Note: MDPI stays neutral with regard to jurisdictional claims in published maps and institutional affiliations.

Copyright: (c) 2021 by the authors. Licensee MDPI, Basel, Switzerland. This article is an open access article distributed under the terms and conditions of the Creative Commons Attribution (CC BY) license (https:// creativecommons.org/licenses/by/ $4.0 /)$.

\begin{abstract}
This study aimed to analyze the essential oils of the aerial parts (A) and flowers (F) of Rosa banksiae var. banksiae Ait. (RBW), Rosa polyantha Thunb. "orange fairy" (RPO) and Rosa polyantha Thunb. "white fairy" (RPW), family Rosaceae, and perform multivariate data analyses and antimicrobial activity evaluations. The essential oil analyses were performed by GC/FID and GC/MS. Principal component analysis (PCA), hierarchical cluster analysis (HCA), and clustered heat map were used for the multivariate analyses. The antimicrobial activity was evaluated by the well-diffusion method against four bacteria and four fungi. Two hundred fifty-three compounds were identified from the six oil samples. The major components in RBW-A, RPO-A, and RPW-A were $n$-undecane $(14.40,19.36$, and $9.21 \%) n$-dodecane $(14.54,22.13$, and $8.39 \%)$, and yomogi alcohol $(8.41,10.53$, and $6.28 \%)$, respectively, whereas RBW-F, RPO-F and RPW-F contained $n$-heptadecane (16.70\%), n-undecane (7.98\%), and $\beta$-phellandrene (22.78\%), respectively. The tested essential oils showed moderate antifungal activity against Aspergillus fumigatus compared to amphotericin B. PCA and HCA revealed five main clusters. The six samples carried close chemical profiles and can be regarded as fruitful sources of safe antifungal agents.
\end{abstract}

Keywords: Rosa species; aspergillosis; essential oil; chemometrics; clustered heat map

\section{Introduction}

Family Rosaceae is composed of 100 genera and 3400 species of herbs, shrubs, and trees, whereas the genus Rosa comprises over 250 species [1]. Traditionally, Rosa banksiae var. banksiae Ait. was used for its antifungal activity, while Rosa polyantha Thunb. leaves were used as a poultice applied to sores and for skincare. The ability of Rosa species to control microbes may be attributed to their high content of vitamin C, in hips and flowers, and other different phenolic and flavonoid constituents [2]. Indigenous people in North America traditionally used roses for cough treatment, especially in children as a decoction and inhalation therapy [3], while ancient Chinese utilized Rosa as a healing plant for sore throat and common cold due to its immune-stimulatory activity [4].

Rosa banksiae var. banksiae Ait. (RBW), known as White Lady Banks or Bankasian Rose, is widely cultivated in China [5]. Its leaves and flowers were reported to have antioxidant, analgesic, and wound-healing properties [6]. Rosa polyantha Thunb. (syn. Rosa multiflora Thunb.) [7] from the Greek (poly = many and anthos = flowers) usually blooms heavily and its roses come in many colors as white, orange, pink, red, yellow, and gold [8]. Several studies have reported the antioxidant and antibacterial activities of $R$. polyantha phenolic-rich extract $[9,10]$. The presence of drug-resistant pathogens is considered one of the important threats that may be faced in the treatment of diseases. Drug-resistant bacteria and fungi usually arise due to antibiotic misuse, poor hygienic practices, and bacterial and fungal mutations that lead to poor response to chemically based antimicrobial agents [11]. Bacteria such as Staphylococcus aureus, Bacillus subtilis, Escherichia coli, and 
Salmonella sp. are considered as common causes of many skin, lung, gastrointestinal, and urinary tract infections [12], while Aspergillus fumigatus is a saprophytic fungal strain that naturally inhabits the soil, spreads in the form of conidia, and may readily cause a serious infection called Aspergillosis in immunocompromised persons [13]. Essential oils play an important role as safe, efficient, and economic antimicrobial agents [14]. Essential oils rich in oxygenated terpenoids such as citronellol, geraniol, nerol, and thymol were reported to kill Aspergillus fungus through absorption into its body in the gaseous phase [13].

Recently, chemometrics has come into widespread use as an analytical tool for data discrimination [15]. Principal component analysis (PCA) and hierarchical cluster analysis (HCA) are two powerful tools for unsupervised data analysis without previous knowledge of the samples. PCA is used to discriminate large datasets while keeping their maximum variation just by clustering them according to related variables in between them [16], while HCA provides means to differentiate different groups into close clusters and subclusters according to their similarity level [17]. The application of chemometrics to plant metabolomics discrimination has gained much interest in recent years as a way to statistically cluster closely related samples according to their relative components, providing easy and efficient bioanalytical data analysis and representation [18].

This study aimed to identify the volatile profile obtained from the aerial parts and flowers of the most commonly cultivated Rosa species, belonging to family Rosaceae. Inparticular, Rosa banksiae var. banksiae Ait. (RBW), Rosa polyantha Thunb. "orange fairy" (RPO), and Rosa polyantha Thunb. "white fairy" (RPW), using GC/FID and GC/MS analyses coupled to multivariate data analysis, viz. PCA, HCA, and clustered heat map for differentiating the related species and varieties together with the evaluation of their antimicrobial activities. It should be noted that Rosa polyantha volatiles were evaluated herein for the first time.

\section{Results and Discussion}

\subsection{Identification of the Essential Oil Components}

The average yields of the hydro-distilled essential oils of RBW, RPW, and RPO essential oils, in terms of dry weight, were $0.25 \pm 0.01,0.47 \pm 0.02$, and $0.39 \pm 0.01 \mathrm{~mL} / 100 \mathrm{~g}$ dry weight for the aerial parts and $0.26 \pm 0.02,0.29 \pm 0.02$, and $0.25 \pm 0.01 \mathrm{~mL} / 100 \mathrm{~g}$ dry weight for the flowers, respectively (these values are expressed as mean $\pm \mathrm{SD}$ of triplicate measurement). The essential oils were pale yellow in color and lighter than water. A total of 253 compounds were identified, as shown in Table S1; their GC-chromatograms are presented in Figures S1-S3 (see supplementary material Table S1, Figures S1-S3). Fatty acidderived volatiles represented the major class in all samples, followed by the oxygenated monoterpenes. This was following all other reported Rosa species essential oils [19-23] as $R$. damascena and $R$. canina where hydrocarbons were the dominant class. For a simpler representation, the most abundant compounds (26) are compiled in Table 1. 
Table 1. Volatile constituents identified from the essential oils of the aerial parts and flowers of the three Rosa varieties (the most abundant components $\geq 2 \%$ ).

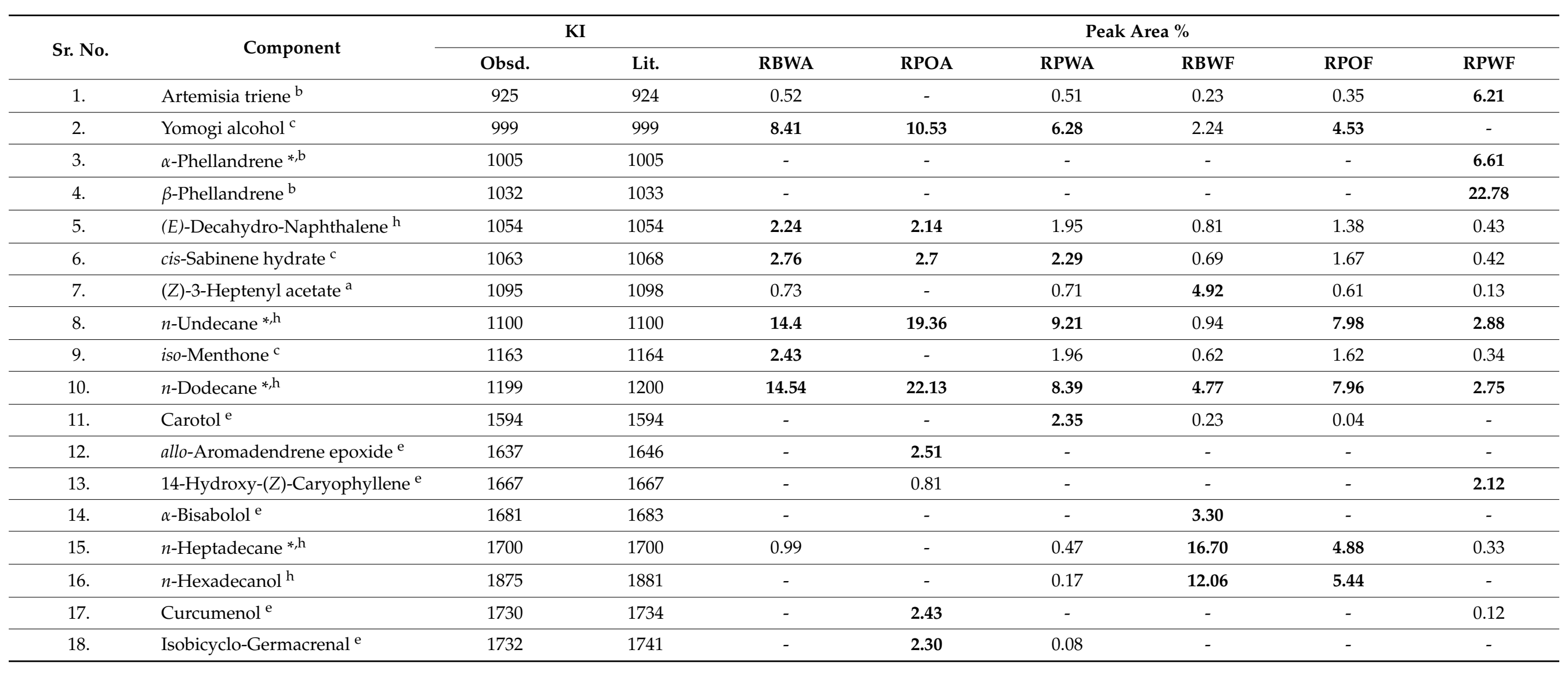


Table 1. Cont.

\begin{tabular}{|c|c|c|c|c|c|c|c|c|c|}
\hline \multirow{2}{*}{ Sr. No. } & \multirow{2}{*}{ Component } & \multicolumn{2}{|c|}{ KI } & \multicolumn{6}{|c|}{ Peak Area \% } \\
\hline & & Obsd. & Lit. & RBWA & RPOA & RPWA & RBWF & RPOF & RPWF \\
\hline 19. & $n$-Nonadecane ${ }^{*, h}$ & 1900 & 1900 & 0.91 & - & 0.29 & 11.55 & 5.78 & 0.2 \\
\hline 20. & Hexadecanoic acidmethyl ester ${ }^{a}$ & 1920 & 1916 & - & - & - & 2.04 & 0.76 & 0.09 \\
\hline 21. & $n$-Heneicosane $*$ h & 2101 & 2100 & 0.91 & - & 0.33 & 8.00 & 5.18 & 1.04 \\
\hline 22. & Laurenan-2-one ${ }^{\mathrm{h}}$ & 2120 & 2116 & 0.71 & 3.40 & 0.37 & - & - & 0.08 \\
\hline 23. & $n$-Tricosane $*$ h & 2301 & 2300 & 1.98 & - & 0.28 & 2.71 & 3.45 & 2.40 \\
\hline 24. & $n$-Pentacosane $*, h$ & 2500 & 2500 & 1.80 & - & 0.54 & 1.56 & 2.70 & 2.11 \\
\hline 25. & Heptacosane *,h & 2700 & 2700 & 2.02 & - & 0.51 & 0.42 & 0.85 & 2.35 \\
\hline 26. & Nonacosane ${ }^{*, h}$ & 2885 & 2900 & 1.99 & - & 0.38 & - & 0.11 & 0.16 \\
\hline \multicolumn{4}{|c|}{ Total identified (\%) } & 89.61 & 94.83 & 85.76 & 93.55 & 92.54 & 94.66 \\
\hline
\end{tabular}

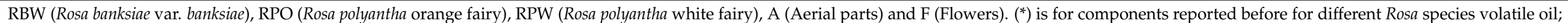
bolded numbers for components with concentrations $\geq 2 \%$. a: fatty acid-derived volatiles, b: monoterpene hydrocarbons, c: oxygenated monoterpenes, e: oxygenated sesquiterpenes, $\mathrm{h}$ : miscellaneous. 
Comparing the analyzed data with those reported, the essential oil of $R$. banksiae Ait. flowers cultivated in China was analyzed by [6] and only 46 compounds were identified. In particular, the main constituents were dodecane (41.01\%), 2-bornanone (26.34\%), phenyl ethyl alcohol $(5.78 \%)$, octane $(4.73 \%)$, borneol (3.78\%), elemicin $(3.01 \%)$, cis-verbenol $(2.68 \%), \alpha$-cadinol $(1.06 \%)$, and 6-methyl dodecane $(1.00 \%)$. In contrast, 71 compounds were identified in this study of $R$. banksiae cultivated in Egypt with full quantitation of each component and different essential oil compositions.

Quantities of monoterpene hydrocarbon in all groups were very small except in RPWF. Oxygenated sesquiterpenes were average in all samples, reaching $12 \%$ except in RBW-A, while phenylpropanoids/aromatics were present in the smallest quantities in all samples together with carotenoids and sesquiterpene hydrocarbons.

Fatty acid-derived volatiles were represented by relatively high quantities of $n$ dodecane and $n$-undecane in all aerial part samples together with laurenan-2-one, while in the flower samples they were represented as (Z)-3-Heptenyl acetate, $n$-heptadecane, $n$-hexadecanol, $n$-nonadecane, $n$-heneicosane, and $n$-tricosane in addition to $n$-dodecane and $n$-undecane.

Monoterpene hydrocarbons were represented by $\beta$-phellandrene (22.78\%), $\alpha$-phellandrene $(6.61 \%)$, and artemisia triene (6.21\%) and were predominant in RPW-F. Nevertheless, yomogi alcohol, representing the oxygenated monoterpenes, predominated in all the tested samples except RPW-F. Alpha-bisabolol (oxygenated sesquiterpene) was only present in the RBW-F samples $(3.30 \%)$.

The dominant compounds in the essential oil of RBW-A were $n$-dodecane (14.54\%), $n$-undecane $(14.40 \%)$, and yomogi alcohol $(8.41 \%)$. Meanwhile, the following represented the major compounds in RBW-F: $n$-heptadecane $(16.70 \%)$, $n$-hexadecanol $(12.06 \%), n$ nonadecane $(11.55 \%)$, and $n$-heneicosane $(8.00 \%)$.

Among the chief components isolated and identified from the RPO-A essential oil were $n$-dodecane $(22.13 \%), n$-undecane $(19.36 \%)$, and yomogi alcohol $(10.53 \%)$. The major compounds in RPO-F were $n$-undecane (7.98\%), $n$-dodecane $(7.96 \%), n$-nonadecane $(5.78 \%)$, $n$-hexadecanol (5.44\%) and $n$-heneicosane (5.18\%).

RPW-A showed unique composition; the essential oil was rich in $n$-undecane $(9.21 \%)$, $n$-dodecane $(8.39 \%)$, and yomogi alcohol $(6.28 \%)$, while the flowers of RPW-F essential oil were rich in $\beta$-phellandrene (22.78\%), $\alpha$-phellandrene (6.61\%), and artemisia triene (6.21\%).

The chemical composition of the studied essential oils showed an abundance of hydrocarbons, which was in accordance with reports on most other tested Rosa species essential oils [19] such as $R$. damascena [24] and R. canina, where hydrocarbons were the dominant class, while other studies addressed the abundance of oxygenated hydrocarbons viz. citronellol in R. damascena petals [25] and citronellol and geraniol in $R$. damascena and $R$. alba [26]. The composition pattern for any essential oil is influenced by many factors, which may be related to the plant, viz. genetics, plant part, sampling season, growth stage, and plant physiology or related to the environment such as climate, cultivation conditions, soil, temperature, humidity and many other factors. This may explain the variation discussed above between the three varieties and between the essential oils from the aerial parts and flowers of the same variety [27]. It is worth noting that polyantha rose essential oil content has not been reported before in the literature and, to the best of our knowledge, this is the first study comparing those three chosen Rosa samples' essential oils in two different organs.

\subsection{Screening for Antimicrobial Activity}

All essential oil samples showed weak activity against S. aureus (RCMB010010) compared to ampicillin, with an inhibition zone of $c a .10 .2 \mathrm{~mm}$, while RPW-F showed no activity against the aforementioned bacteria. On the other hand, other tested essential oils showed no activity against B. subtilis (RCMB 010067). Nevertheless, Salmonella sp. (RCMB 010043) and E. coli (RCMB 010052) showed resistance against all tested essential oils except RBW-A and RPO-F with $c a .8 \mathrm{~mm}$ inhibition zone relative to the standard 
used. The essential oils obtained from the aerial parts and flowers of RBW, RPO, and RPW showed moderate activity against $A$. fumigates (RCMB 002008) compared to amphotericin $B$, while other tested fungal strains showed resistance to all samples (Table 2). As noted above, the fatty acid-derived volatile content dominated all isolated essential oils, which might explain their weak antibacterial activity. Differences in climate, harvest time, and cultivation conditions led to variable essential oil content [28-30], which resulted in varying degrees of antimicrobial activity.

Table 2. Antimicrobial activity of aerial parts and flower volatile oils of Rosa varieties expressed as the diameter of one of inhibition in $\mathrm{mm}$.

\begin{tabular}{|c|c|c|c|c|c|c|c|}
\hline Tested Microorganisms & RBW-A & RPO-A & RPW-A & RBW-F & RPO-F & RPW-F & Control \\
\hline Gram-Positive Bacteria & & & & & & & Ampicillin \\
\hline $\begin{array}{l}\text { Staphylococcus aureus } \\
\text { (RCMB010010) }\end{array}$ & 11 & 8 & 8 & 11 & 13 & NA & 23 \\
\hline $\begin{array}{l}\text { Bacillus subtilis } \\
\text { (RCMB 010067) }\end{array}$ & 8 & NA & NA & NA & 8 & NA & 32 \\
\hline Gram-Negative Bacteria & & & & & & & Gentamicin \\
\hline Salmonella sp. (RCMB 010043) & NA & NA & NA & NA & NA & NA & 17 \\
\hline Escherichia coli (RCMB 010052) & NA & NA & NA & NA & NA & NA & 19 \\
\hline Fungi & & & & & & & Amphotericin B \\
\hline $\begin{array}{c}\text { Aspergillus fumigatus (RCMB } \\
\text { 002008) }\end{array}$ & 14 & 15 & 11 & 14 & 15 & 12 & 23 \\
\hline Candida albicans (RCMB 05036) & NA & NA & NA & NA & NA & NA & 25 \\
\hline $\begin{array}{c}\text { Syncephalastrum racemosum } \\
\text { (RCMB 016001) }\end{array}$ & NA & NA & NA & NA & NA & NA & 20 \\
\hline $\begin{array}{l}\text { Penicillium aurantiogriseum } \\
\text { (RCMB 001002) }\end{array}$ & NA & NA & NA & NA & NA & NA & 21 \\
\hline
\end{tabular}

RBW (Rosa banksiae var. banksiae Ait.), RPO (Rosa polyantha Thunb. "orange fairy"), RPW (Rosa polyantha Thunb. "white fairy"), A (aerial parts), F (Flowers), NA (not active).

2.3. Multivariate Data Analysis Using Principal Component Analysis (PCA), Hierarchical Cluster Analysis (HCA), and Clustered Heat Map

PCA and HCA were evaluated for the area percentage of the identified compounds. PCA analysis gave rise to five different clusters (Figure 1A,B) where the variance was $52 \%$ for PC1 and 39\% for PC2. RBW-A and RPW-A were located in one cluster in the left upper quadrant, while the aerial parts of RPO were located separately in another cluster in the same quadrant. The three flower samples appeared separately in three different clusters: RBW-F and RPO-F in the right lower quadrant and RPW-F to the right in the upper quadrant. Taking into consideration that the RPO-F cluster was somewhat near the RBW-A and RPW-A clusters, the presence of a considerably rich quantity of $n$-undecane as a common component in RPO-A led to its positioning in a single cluster, yet near to the aforementioned cluster. The previously described pattern may be attributed to differences in composition between the samples where the unique abundance of $n$-dodecane and $n$ undecane implied an effect in the clustering of RBW-A and RPW-A together. Additionally, the unique presence of $n$-heptadecane in RBW-F and $\beta$-phellandrene in RPW-F had a powerful discriminating effect for their positioning, each in a single cluster, away from the other essential oil samples. 

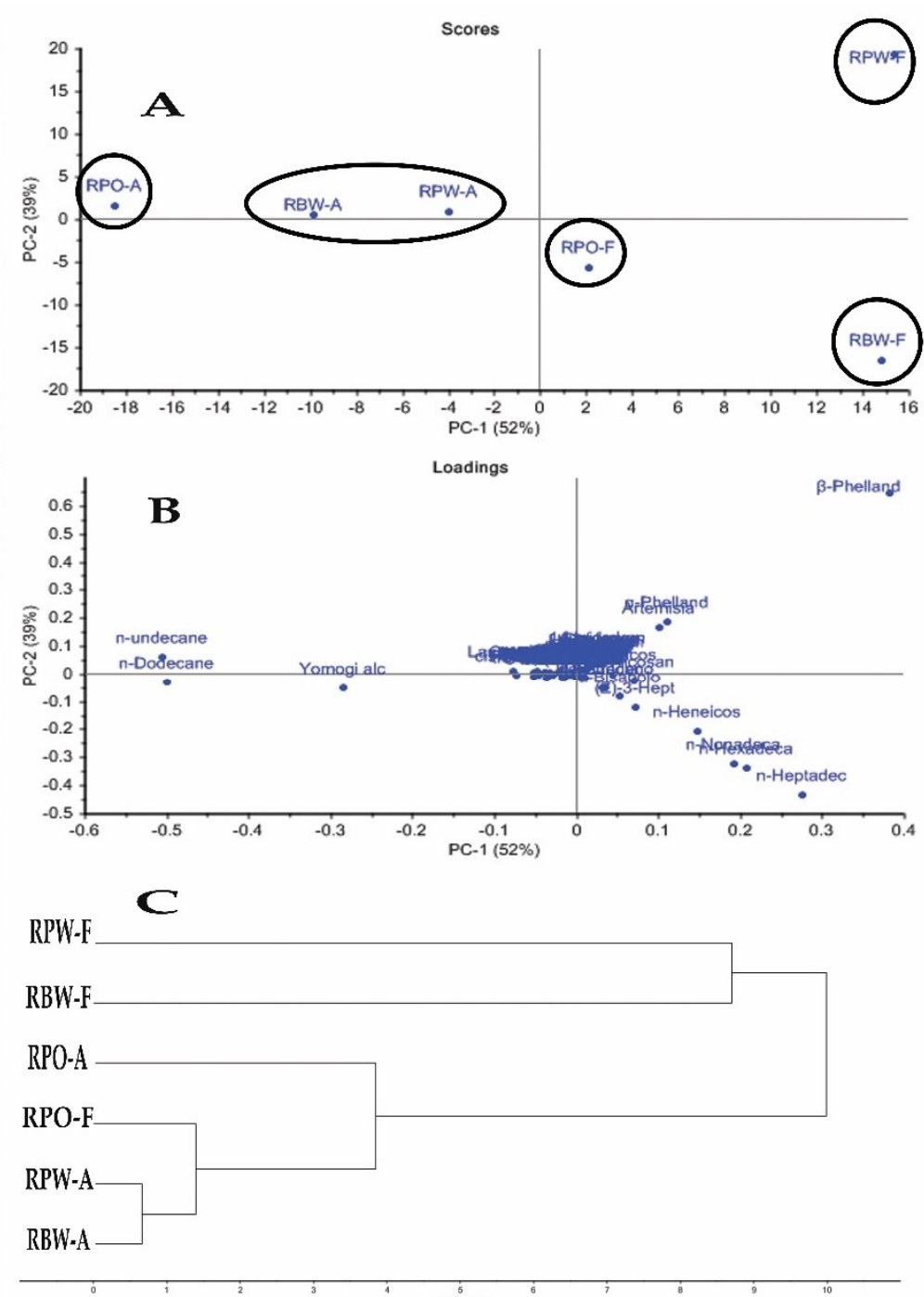

Figure 1. (A) Score plot of PC1 versus PC2 of the volatiles obtained from aerial parts and flowers of different Rosa varieties' essential oils analyzed by GC/MS $(n=6)$ (area \% as a variable). (B) Loading plot for PC1 and PC2 contributing volatiles and their assignments (area \% as variable). (C) Dendrogram illustrates the clustering of different aerial part and flower essential oils of different Rosa varieties (area \%). [RBW (Rosa banksiae var. banksiae Ait.), RPO (Rosa polyantha Thunb. "orange fairy"), RPW (Rosa polyantha Thunb. "white fairy"), A (aerial parts), F (Flowers)].

Concerning HCA, (Figure 1C) using area percentage revealed the closeness of composition between RBW-A and RPW-A, which were in line with PCA score plot values.

Applying further multivariate analysis with the help of clustered heat map (double dendrogram) where only compounds with area percentage $\geq 1 \%$ were included, the color pattern ranged from blue for the lowest area percentage and the color intensity increased gradually until red for the highest area percentage. The clustered heat map (Figure 2) confirmed the clustering results discussed above for PCA and HCA using area percentage as a variable. It was clear that the components with the highest percentage (denoted with red in the clustered heat map) in RBW-A and RPW-A were almost the same and accounted for their grouping together. 


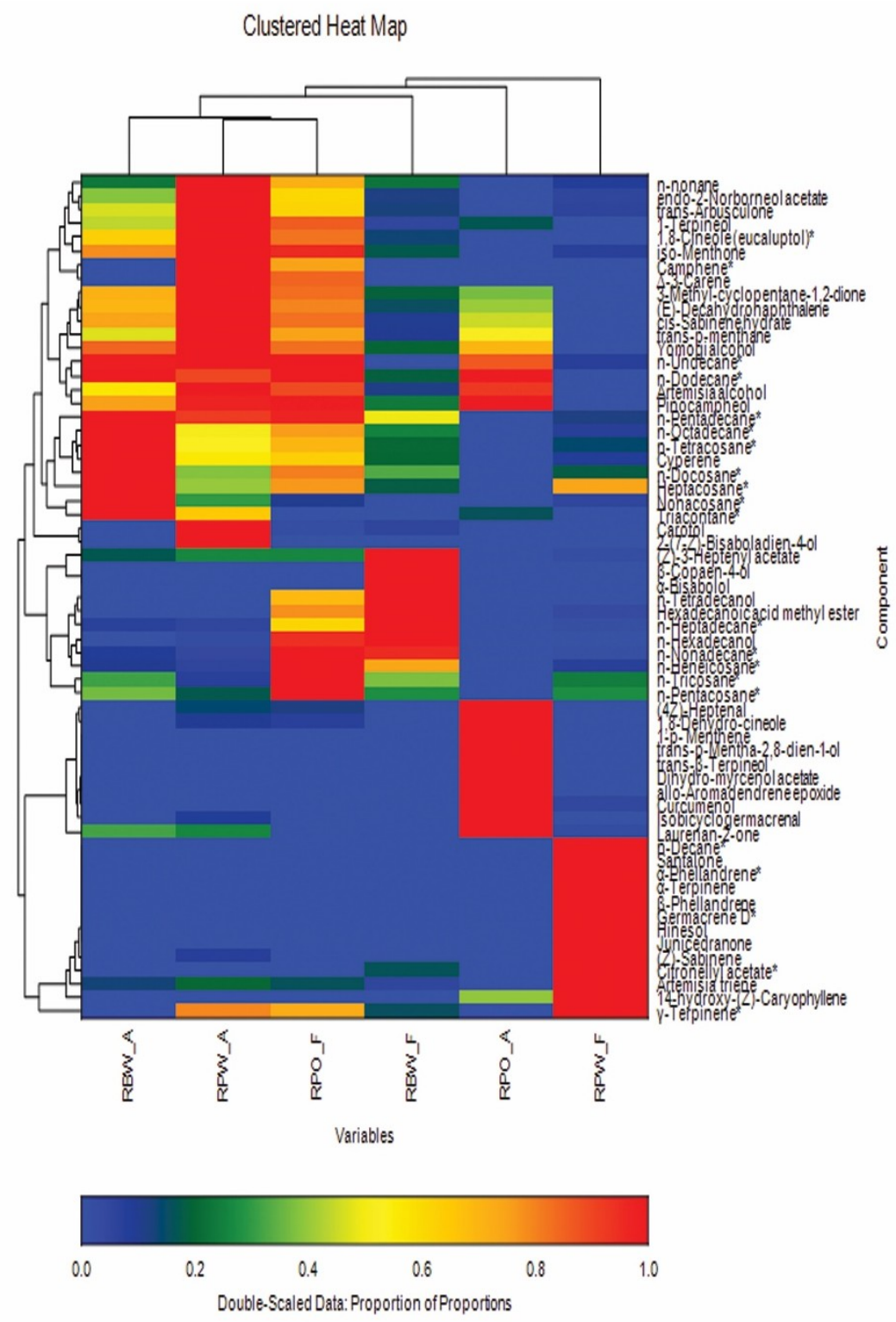

Figure 2. Clustered heat map showing the volatile components of the six studied Rosa samples. A heat map was constructed using Euclidean distance and the unweighted group method. Compounds with \% composition of at least 1\% were included. [RBW (Rosa banksiae var. banksiae Ait.), RPO (Rosa polyantha Thunb. "orange fairy"), RPW (Rosa polyantha Thunb. "white fairy"), A (aerial parts), F (Flowers)].

On the other hand, based on the variation in composition, the essential oils of RPOA, RBW-F, RPO-F, and RPW-F generated a particular arrangement in the heat map by following the pattern obtained from PCA and HCA relying on area percentage.

Plants can be a source of many bioactive metabolites [29], the profiling of which may also help in their discrimination from other inter-related species. Variation of rose essential oil chemical composition was previously studied in Tunisia for flowers of $R$. canina L. and $R$. sempervirens L., and this variability may be attributed to different cultivation localities [28]. PCA was previously applied as a chemometric tool to discriminate between different $R$. damascena Mill. genotypes [31]. PCA showed no clear clustering for different $R$. alba L. genotypes [32,33]. Multivariate analysis was used for fingerprinting of 12 R. multiflora genotypes, as described by [34]. 


\section{Materials and Methods}

\subsection{Plant Material}

Aerial parts (500 g) and flowers (50 g) of Rosa banksiae var. banksiae Ait. (syn. Rosa banksiae R.Br.) (RBW), known as Banksian rose, were collected from Merryland Botanical Garden, Cairo, Egypt $\left(30^{\circ} 05^{\prime} 37^{\prime \prime} \mathrm{N}, 31^{\circ} 18^{\prime} 51^{\prime \prime} \mathrm{E}\right)$, while Rosa polyantha Thunb. "orange fairy" (syn. Rosa multiflora Thunb.) (RPO) and Rosa polyantha Thunb. "white fairy" (syn. Rosa multiflora Thunb.) (RPW) were collected from a private garden, Al-Mariouteya Road, Kirdassa, Giza, Egypt $\left(30^{\circ} 01^{\prime} 13^{\prime \prime} \mathrm{N}, 31^{\circ} 04^{\prime} 42^{\prime \prime}\right.$ E). The samples were collected during March-April 2016 (flowering season) and were authenticated by agricultural engineer Terease Labib, Consultant of Plant Taxonomy at the Ministry of Agriculture, El-Orman Botanical Garden, and National Gene Bank, Giza, Egypt, and Mahmoud Abo El Nile, botanical consultant, Merryland Botanical Garden, Cairo, Egypt. Voucher specimens were kept under codes: (PHG-P-RB 165), (PHG-P-RP 205), and (PHG-P-RP 204) for RBW, RPO, and RPW, respectively, at the Herbarium of Pharmacognosy Department, Faculty of Pharmacy, Ain Shams University, Cairo, Egypt.

\subsection{Isolation of Essential Oil Samples}

Fresh aerial parts $(500 \mathrm{~g})$ and flowers $(50 \mathrm{~g})$ from each of the chosen samples were collected and cut into small pieces, then hydro-distilled using Clevenger-type apparatus, according to the Egyptian pharmacopeia [35], by boiling for $4 \mathrm{~h}$. The essential oils were then collected and stored in sealed vials in the freezer at $-4{ }^{\circ} \mathrm{C}$ until needed. The hydrodistillation was performed thrice. The collected essential oil samples were treated with anhydrous sodium sulfate to remove excess moisture.

\subsection{Gas Chromatography Analysis \\ 3.3.1. GC/FID Analysis}

Essential oil GC/FID analysis was performed using a method described by $[30,36,37]$ as follows: GC analysis was accomplished using a GC HP 5890 Hewlett Packard equipped with FID and RTX-5 fused silica capillary column ( $30 \mathrm{~m} \times 0.25 \mathrm{~mm}$ i.d., film thickness $0.25 \mu \mathrm{m}$ ). Sample volume: $0.2 \mu \mathrm{L}$ of diluted sample (1:10 hexane, $v / v)$. The oven temperature was programmed from $45{ }^{\circ} \mathrm{C}$ to $300{ }^{\circ} \mathrm{C}$ at $3{ }^{\circ} \mathrm{C} / \mathrm{min}$; injector temperature, $300{ }^{\circ} \mathrm{C}$; detector temperature, $280^{\circ} \mathrm{C}$; carrier gas, helium $(1.0 \mathrm{~mL} / \mathrm{min})$; automatic sample injection, $0.2 \mu \mathrm{L}$ of diluted sample (1:10 hexane, $v / v$ ) of the essential oil; split: $1 / 70$. The oven temperature was programmed from $45^{\circ} \mathrm{C}$ to $300^{\circ} \mathrm{C}$ at $3{ }^{\circ} \mathrm{C} / \mathrm{min}$; injector temperature, $300{ }^{\circ} \mathrm{C}$; carrier gas, helium $(0.5 \mathrm{~mL} / \mathrm{min})$; automatic sample injection, $0.02 \mu \mathrm{L}$ of the essential oil; split: $1 / 70$. The MS operating parameters were: interface temperature: $300{ }^{\circ} \mathrm{C}$, ion source temperature: $200{ }^{\circ} \mathrm{C}$, EI mode: $70 \mathrm{eV}$, scan range: $45-500 \mathrm{amu}$.

\subsubsection{GC/MS Analysis}

Essential oils $(0.2 \mu \mathrm{L}$ of diluted samples (1:10 hexane, $v / v))$ were injected. GC/MS analysis was performed on a PerkinElmer quadrupole MS system (Model 5) coupled with the GC HP 5972, equipped with an RTX-5 capillary column. The resulting compounds were identified and defined according to their corresponding mass spectral fragmentation and Kovats' indices when compared to available literature, references as Adams [38], computer library (NIST-11 Mass Spectral Library), and research articles [39,40]. The components were identified by matching their mass spectra value to the NIST library, which was then confirmed by comparing with the Kovats' index on the RTX-5 column. Kovats' indices were calculated from a series of hydrocarbon $n$-alkanes $\left[\mathrm{C}_{8}-\mathrm{C}_{28}\right]$.

The following formula was used for RI calculation:

$$
\mathrm{RI}=100\left[\mathrm{n}+(\mathrm{N}-\mathrm{n}) \mathrm{x}\left[\frac{\log \mathrm{Rt}(\text { sample })-(\log \mathrm{Rt}(\mathrm{n}) /(\mathrm{N})}{(\log \mathrm{Rt}(\mathrm{N})-(\log \mathrm{Rt}(\mathrm{n})}\right]\right.
$$

where: 
$\mathrm{RI}=$ retention time of the identified compound.

$\mathrm{N}=$ no. of carbon atoms in the larger alkane.

$\mathrm{n}=$ no. of carbon atoms in the smaller alkane.

\subsection{Antimicrobial Screening}

\subsubsection{Microorganisms}

The following microbial strains were used in the screening, viz. Gram-positive bacterial strains as Staphylococcus aureus (RCMB010010) and Bacillus subtilis (RCMB 010067); Gramnegative bacterial strains as Salmonella sp. (RCMB 010043) and Escherichia coli (RCMB 010052); four fungi as Aspergillus fumigatus (RCMB 002008), Candida albicans (RCMB 05036), Syncephalastrum racemosum (RCMB 016001), and Penicillium aurantiogriseum (RCMB 001002). They were purchased from the Regional Center for Mycology and Biotechnology (RCMB), Cairo, Egypt. All strains were maintained in a viable state.

\subsubsection{Well-Diffusion Method}

Screening tests regarding the inhibition zones were carried out by the agar well- diffusion method according to National Committee for Clinical Laboratory Standards [41,42]. Colonies grown overnight on an agar plate were used for inoculum suspension preparation and inoculated into Mueller-Hinton broth and malt broth for bacterial and fungal strains, respectively. Each sample of essential oils was tested at a $5 \mathrm{mg} / \mathrm{mL}$ concentration. The essential oil samples were dissolved in dimethylsulfoxide (DMSO), and $100 \mu \mathrm{L}$ was added to each well, which was $6 \mathrm{~mm}$ in diameter. Then, inhibition zones were measured around each well after incubation for $24 \mathrm{~h}$ at $37{ }^{\circ} \mathrm{C}$ for bacteria and $28{ }^{\circ} \mathrm{C}$ for fungi. Controls using DMSO were adequately prepared. Results were compared with reference drugs, viz. amphotericin B, gentamicin (Sigma Chemical Co., St. Louis, MO, USA), and ampicillin G (Oxoid, UK).

\subsection{Multivariate Data Analysis}

Techniques used were unsupervised principal component analysis (PCA) and hierarchical cluster analysis (HCA), using Unscrambler 9.7 (CAMO SA, Oslo, Norway) for PCA and Hierarchical Clustering Explorer 3.5 (Human-computer interaction laboratory, University of Maryland, College Park, MD, USA) for HCA. A clustered heat map was constructed using NCSS. 12 software with Euclidean distance and the unweighted pair group method.

\section{Conclusions}

The metabolomic profiles of the essential oils (aerial parts and flowers) obtained from RBW, RPW, and RPO family Rosaceae were evaluated through GC/FID and GC/MS analyses, and a total of 253 compounds were identified, both qualitatively and quantitatively. Hydrocarbon terpenoids were the predominant class identified in the six samples except for RPWF, where oxygenated terpenoids were the most abundant. Moderate antifungal activity was traced for all the samples against Aspergillus fumigatus but weak activity or no activity was observed against some Gram-positive and Gram-negative bacteria. PCA and HCA results showed that RBW-A and RPW-A were clustered together due to their very close chemical composition compared to the other studied essential oil samples, and this was further confirmed by the clustered heat map.

Supplementary Materials: The following are available online at https://www.mdpi.com/article/10 .3390 / plants10081721/s1, Table S1. Volatile constituents identified in the volatile oils of the aerial parts and flower of different Rosa varieties, Figure S1. GC-chromatogram of the essential oil of Rosa banksiae var. banksiae Ait. (A) Aerial parts (RBW-A), (B) Flowers (RBW-F), Figure S2. GCchromatogram of the essential oil of Rosa polyantha Thunb. 'orange fairy' (A) Aerial parts (RPO-A), (B) Flowers (RPO-F), Figure S3. GC-chromatogram of the essential oil of Rosa polyantha Thunb. 'white fairy' (A) Aerial parts (RPW-A), (B) Flowers (RPW-F). 
Author Contributions: Investigation, methodology, writing—original draft, E.A.E.; methodology, supervision, validation, writing - review and editing, N.M.M., R.M.L.; conceptualization, supervision, writing-review and editing, A.N.S.; equal contribution, E.A.E., N.M.M. contributed equally to this work. All authors have read and agreed to the published version of the manuscript.

Funding: This research received no external funding.

Institutional Review Board Statement: Not applicable.

Informed Consent Statement: Not applicable.

Data Availability Statement: Data are available upon request from the authors.

Conflicts of Interest: The authors declare no conflict of interest.

\section{References}

1. Xiang, Y.; Huang, C.H.; Hu, Y.; Wen, J.; Li, S.; Yi, T.; Chen, H.; Xiang, J.; Ma, H. Evolution of Rosaceae fruit types based on nuclear phylogeny in the context of geological times and genome duplication. Mol. Biol. Evol. 2017, 34, 262-281. [CrossRef]

2. Pathak, D.; Dave, K.M.; Aliasgar, L. Antimicrobial properties of Rosa indica (A New Start with Nature). Biosci. Biotechnol. Res. Asia 2019, 16, 403-409. [CrossRef]

3. Ayati, Z.; Amiri, M.S.; Ramezani, M.; Delshad, E.; Sahebkar, A.; Emami, S.A. Phytochemistry, traditional uses and pharmacological profile of rose hip: A review. Curr. Pharm. Des. 2018, 24, 4101-4124. [CrossRef] [PubMed]

4. Mahomoodally, M.F.; Muthoorah, L.D. An ethnopharmacological survey of natural remedies used by the Chinese community in Mauritius. Asian Pac. J. Trop. Biomed. 2014, 4 (Suppl. 1), S387-S399. [CrossRef] [PubMed]

5. Zeng, C.; Luo, S.; Feng, S.; Chen, T.; Zhou, L.; Yuan, M.; Huang, Y.; Liao, J.; Ding, C. Phenolic composition, antioxidant and anticancer potentials of extracts from Rosa banksiae Ait. Flowers. Molecules 2020, 25, 3068. [CrossRef] [PubMed]

6. Yu, A.N.; Wang, X.P.; Yang, X.H. Chemical composition of the essential oils of flowers of Rosa banksiae from China. Chem. Nat. Compd. 2007, 43, 728-729. [CrossRef]

7. Zhang, J. Plantlist: Looking up the Status of Plant Scientific Names Based on the Plant List Database. R Package Version 0.5. 3. 2019. Available online: https://github.com/helixcn/plantlist (accessed on 1 August 2021).

8. Dadhwal, I. Genotypic Evaluation of Miniature, Polyantha and Floribunda Roses (Rosa hybrida L.) for Pot Culture; Punjab Agricultural University: Ludhiana, India, 2016.

9. Ashatnu, Q.; Hojaaihemaiti, M.; Aimaier, A.; Abulizi, G.; Malike, D. Extraction of polyphenols from Rosa multiflora Thunb. and the study on their antioxidant and antibacterial activity. J. Huazhong Norm. Uni. 2014, 48, 850-856.

10. Frey, F.M.; Meyers, R. Antibacterial activity of traditional medicinal plants used by Haudenosaunee peoples of New York State. BMC Complement. Altern. Med. 2010, 10, 1-10. [CrossRef]

11. Hofer, U. The cost of antimicrobial resistance. Nat. Rev. Microbiol. 2019, 17, 3-33. [CrossRef]

12. Kayser, F.H.; Bienz, K.A.; Eckert, J.; Zinkernagel, R.M. Medical Microbiology; CBS Publishers \& Distributors Pvt. Ltd.: Delhi, India, 2005.

13. Rudramurthy, S.M.; Paul, R.A.; Chakrabarti, A.; Mouton, J.W.; Meis, J.F. Invasive aspergillosis by Aspergillus flavus: Epidemiology, diagnosis, antifungal resistance, and management. J. Fungi 2019, 5, 55. [CrossRef]

14. Shaaban, H.A. Essential Oil as Antimicrobial Agents: Efficacy, Stability, and Safety Issues for Food Application; Essential Oils-Bioactive Compounds, New Perspectives and Applications; Intechopen: London, UK, 2020; pp. 1-33.

15. Farag, M.A.; Labib, R.M.; Noleto, C.; Porzel, A.; Wessjohann, L.A. NMR approach for the authentication of 10 cinnamon spice accessions analyzed via chemometric tools. LWT-Food Sci. Technol. 2018, 90, 491-498. [CrossRef]

16. Bansal, A.; Chhabra, V.; Rawal, R.K.; Sharma, S. Chemometrics: A new scenario in herbal drug standardization. J. Pharm. Anal. 2014, 4, 223-233. [CrossRef] [PubMed]

17. Asri, M.N.M.; Desa, W.N.S.M.; Ismail, D. Combined Principal Component Analysis (PCA) and Hierarchical Cluster Analysis (HCA): An efficient chemometric approach in aged gel inks discrimination. Aust. J. Forensic Sci. 2020, 52, 38-59. [CrossRef]

18. Dai, T.; Chang, X.; Hu, Z.; Liang, L.; Sun, M.; Liu, P.; Liu, X. Untargeted metabolomics based on GC-MS and chemometrics: A new tool for the early diagnosis of strawberry anthracnose caused by Colletotrichum Theobromicola. Plant Dis. 2019, 103, 2541-2547. [CrossRef]

19. Zhu, W.; Mei, H.; Shu, M.; Liao, L.; Yang, J.; Li, Z. Chemical structural characterization of some components from essential oil of Rosa banksiae for estimation and prediction of their retention time. Zhongguo Zhong Yao Za Zhi China J. Chin. Mater. Med. 2008, 33, 609-611.

20. Verma, R.S.; Padalia, R.C.; Chauhan, A.; Singh, A.; Yadav, A.K. Volatile constituents of essential oil and rose water of damask rose (Rosa damascena Mill.) cultivars from North Indian hills. Nat. Prod. Res. 2011, 25, 1577-1584. [CrossRef]

21. Xiao, Z.; Luo, J.; Niu, Y.; Wu, M. Characterization of key aroma compounds from different rose essential oils using gas chromatography-mass spectrometry, gas chromatography-olfactometry and partial least squares regression. Nat. Prod. Res. 2018, 32, 1567-1572. [CrossRef] 
22. Mohamadi, M.; Mostafavi, A.; Shamspur, T. Effect of storage on essential oil content and composition of Rosa damascena Mill. petals under different conditions. J. Essent. Oil Bear. Plants 2011, 14, 430-441. [CrossRef]

23. Moein, M.; Ghasemi, Y.; Karami, F.; Tavallali, H. Composition of the essential oil of Rosa damascenea Mill. from South of Iran. Iran. J. Pharma Sci. 2010, 6, 59-62.

24. Marekov, B.S.I.N.; Mondeshky, L.; Zolotovitch, G. Biogenesis of alkanes in the flowers of the essential oil rose (Rosa damascena MILL.). Phytochemistry 1968, 7, 231-234. [CrossRef]

25. Wei, A.; Shibamoto, T. Antioxidant activities and volatile constituents of various essential oils. J. Agric. Food Chem. 2007, 55, 1737-1742. [CrossRef]

26. Dobreva, A.; Velcheva, A.; Bardarov, V.; Bardarov, K. Chemical composition of different genotypes oil-bearing roses. Bulg. J. Agric. Sci. 2013, 19, 1213-1218.

27. Moghaddam, M.; Mehdizadeh, L. Chemistry of Essential Oils and Factors Influencing Their Constituents, in Soft Chemistry and Food Fermentation; Elsevier: Amsterdam, The Netherlands, 2017; pp. 379-419.

28. Ghazghazi, H.; Miguel, M.G.; Weslati, M.; Hasnaoui, B.; Sebei, H.; Barroso, J.; Pedro, L.; Figueiredo, A. Chemical variability of the essential oils from Rosa canina L. and Rosa sempervirens L. flowers collected at Tunisia. J. Essent. Oil Res. 2012, 24, 475-480. [CrossRef]

29. Inouye, S.; Yamaguchi, H.; Takizawa, T. Screening of the antibacterial effects of a variety of essential oils on respiratory tract pathogens, using a modified dilution assay method. J. Infect. Chemother. 2001, 7, 251-254. [CrossRef]

30. Ashmawy, A.; Mostafa, N.; Eldahshan, O. GC/MS analysis and molecular profiling of lemon volatile oil against breast cancer. J. Essent. Oil Bear. Plants 2019, 22, 903-916. [CrossRef]

31. Gorji-Chakespari, A.; Nikbakht, A.M.; Sefidkon, F.; Ghasemi-Varnamkhasti, M.; Valero, E.L. Classification of essential oil composition in Rosa damascena Mill. genotypes using an electronic nose. J. Appl. Res. Med. Aromat. Plants 2017, 4, 27-34. [CrossRef]

32. Rusanov, K.; Kovacheva, N.; Rusanova, M.; Atanassov, I. Flower phenotype variation, essential oil variation and genetic diversity among Rosa alba L. accessions used for rose oil production in Bulgaria. Sci. Hortic. 2013, 161, 76-80. [CrossRef]

33. Mostafa, N.M.; Abd El-Ghffar, E.A.; Hegazy, H.G.; Eldahshan, O.A. New methoxyflavone from Casimiroa sapota and the biological activities of its leaves extract against lead acetate induced hepatotoxicity in rats. Chem. Biodivers. 2018, 15, e1700528. [CrossRef]

34. Tuniyazi, G.; Ablajan, N.; Malike, D.; Hailaxi, A. Gas chromatography-based fingerprinting and chemical pattern recognition of Rosa multiflora volatile oil. J. Agric. Sci. Technol. A 2017, 7, 31-38.

35. Pharmacopoeia, E. General Organization for Governmental; Printing Office, Ministry of Health: Cairo, Egypt, 1984.

36. Mostafa, N.M. Antibacterial activity of ginger (Zingiber officinale) leaves essential oil nanoemulsion against the cariogenic Streptococcus mutans. J. Appl. Pharm. Sci. 2018, 8, 34-41.

37. Ayoub, N.; Singab, A.N.; Mostafa, N.; Schultze, W. Volatile constituents of leaves of Ficus carica Linn. grown in Egypt. J. Essent. Oil Bear. Plants 2010, 13, 316-321. [CrossRef]

38. Adams, R.P. Identification of Essential Oil Components by Gas Chromatography/Mass Spectrometry, 5th ed.; Texensis Publishing: Gruver, TX, USA, 2017.

39. Labib, R.M.; Youssef, F.S.; Ashour, M.L.; Abdel-Daim, M.M.; Ross, S.A. Chemical composition of Pinus roxburghii bark volatile oil and validation of its anti-inflammatory activity using molecular modelling and bleomycin-induced inflammation in albino mice. Molecules 2017, 22, 1384. [CrossRef]

40. Todirascu-Ciornea, E.; El-Nashar, H.A.; Mostafa, N.M.; Eldahshan, O.A.; Boiangiu, R.S.; Dumitru, G.; Hritcu, L.; Singab, A.N.B. Schinus terebinthifolius essential oil attenuates scopolamine-induced memory deficits via cholinergic modulation and antioxidant properties in a zebrafish model. Evid.-Based Complement. Altern. Med. 2019, 2019, 1-11. [CrossRef] [PubMed]

41. NCCLS. Reference Method for Broth Dilution Antifungal Susceptibilty Testing of Filamentous Fungi, Approved Standard, M38-A; National Committee on Clinical Laboratory Standards: Lake Success, NY, USA, 2002; Volume 22.

42. Jorgensen, J.H.; Swenson, J.M.; Tenover, F.C.; Ferraro, M.J.; Hindler, J.A.; Murray, P.R. Development of interpretive criteria and quality control limits for broth microdilution and disk diffusion antimicrobial susceptibility testing of Streptococcus pneumoniae. J. Clin. Microbiol. 1994, 32, 2448-2459. [CrossRef] [PubMed] 